\title{
PENGARUH PERUBAHAN KEBIJAKAN FREE FLOAT TERHADAP HARGA SAHAM PADA IDX30 DAN LQ45
}

\author{
Ninik Kurniasih ${ }^{1)}$, Linda Suherma ${ }^{2)}$, \& Rika Irawati ${ }^{3)}$ \\ ${ }^{1}$ Jurusan Akuntansi Politeknik Negeri Pontianak \\ email: kurniasih_ninik@yahoo.com \\ 2 Jurusan Akuntansi Politeknik Negeri Pontianak \\ email: lindasuherma@yahoo.com \\ ${ }^{3}$ Jurusan Akuntansi Politeknik Negeri Pontianak \\ email: rika_irawati04@yahoo.com
}

\begin{abstract}
Track record of Free Float $(F F)$ policy changes has been regulated by the Indonesia Stock Exchange (BEI) since 2004, 2014 and 2018 and has been re-revised in August 2019. Problems formulated 1) Do the FF policy changes affect the stock price at the time of announcement, weighting and implementation 2) What is the impact of the FF policy changes on the issuers. This research is an explanatory research with a quantitative approach, tested by multiple regression to see whether or not the influence of FF policy on stock price. The results show that the hypothesis test at the time of the announcement stated that the FF ratio affected stock price by 0.02 at the expense of the cigarette and mining industry stocks. At this stage the stocks that benefit from the policy are banking stocks such as BBCA and BBRI. Meanwhile, at the time of applying $70 \%$ and $40 \%$ weights, stated that the FF ratio affected the stock price by 0.04 at the expense of the cigarette industry and consumer good. The stocks that benefited were banking and cement industry stocks. For the implementation of $100 \%$ FF stated that the free float ratio had no effect on the stock price of 0.17, again harming the cigarette industry and the construction sector and benefiting banking, cement and telecommunications stocks.
\end{abstract}

Keywords: free float ratio, issuers, stock price

\section{PENDAHULUAN}

\section{Latar Belakang Penelitian}

Kebijakan free float adalah kebijakan yang berkaitan dengan rasio jumlah saham relatif terhadap total saham tercatat, yaitu total saham scripless yang dimiliki oleh investor dengan kepemilikan pada suatu persentase tertentu. BEI kembali melakukan revisi terhadap kebijakan tersebut pada tahun 2014 melalui Peraturan tertanggal 30 Januari 2014. Aturan ini tertuang dalam keputusan direksi BEI No. Kep. 00001/BEI/01-2014 tentang perubahan peraturan No. 1-A tentang pencatatan saham dan efek yang bersifat ekuitas selain saham yang diterbitkan oleh emiten. Dampak dari peraturan baru tersebut adalah adanya free float menjadi 7,5\%.

Jika sistem ini diterapkan maka akan terjadi kembali penyesuaian bobot bagi saham saham pada kelompok LQ45 dan IDX30 karena jumlah saham beredar ditiap saham ini berbeda beda. Artinya, emiten dengan jumlah free float besar akan memiliki bobot lebih tinggi dibandingkan dengan emiten yang memiliki jumlah free float rendah. Berikut ini adalah tabel tentang rekam jejak kebijakan free float tersebut. 
Tabel 1. Rekam Jejak Kebijakan Free Float BEI

\begin{tabular}{|l|r|l|l|}
\hline Thn/BIn & $\begin{array}{c}\text { Persen } \\
\text { RFF }\end{array}$ & $\begin{array}{l}\text { Nama } \\
\text { Kebijakan }\end{array}$ & Emiten \\
\hline $\mathbf{2 0 0 4}$ & $5 \%$ & CWI & LQ 45 \\
\hline $\mathbf{2 0 1 4}$ & $7,5 \%$ & CWI & LQ 45 \\
\hline $\begin{array}{l}\mathbf{2 0 1 8} \\
\text { (Nov) }\end{array}$ & $10 \%$ & $\begin{array}{l}\text { CWI ke } \\
\text { FFAI }\end{array}$ & $\begin{array}{l}\text { LQ 45 ke } \\
\text { IDX 30 }\end{array}$ \\
\hline $\begin{array}{l}\mathbf{2 0 1 9} \\
\text { (Agst) }\end{array}$ & $5 \%$ & FFAI & IDX 80 \\
\hline
\end{tabular}

Sumber: Data BEI diolah

Keterangan:

$\mathrm{RFF}=$ Rasio Free Float

$\mathrm{CWI}=$ Capitalization Weighted Index

FFAI $=$ Free Float Adjusted Index

Capitalization Weighted Index adalah bobot sebuah saham akan ditentukan dengan membagi kapitalisasi pasarnya dengan total kapitalisasi pasar dari seluruh saham pembentuk indeks. Kapitalisasi pasar dengan metode capitalizationweighted index didapatkan dengan mengalikan seluruh saham yang beredar dengan harganya di pasar sekunder. Sementara free float adjusted index adalah nilai kapitalisasi pasar yang diperoleh dengan cara mengalikan free float (total saham scripless yang dimiliki oleh investor dengan kepemilikan kurang dari 5\%) dengan harganya di pasar sekunder. Kemudian, angka ini dibagi dengan total kapitalisasi pasar free float dari seluruh saham pembentuk indeks untuk mendapatkan bobotnya. Adanya perubahan kebijakan ini dari tahun 2004 sampai tahun 2019 oleh BEI mempunyai tujuan untuk meningkatkan efisiensi portofolio, mendorong perusahaan untuk menambah porsi saham free float, serta mengurangi dominasi suatu saham dalam perhitungan indeks.

Aturan yang diberlakukan pada Agustus 2019 memancing para investor untuk melepas saham yang memiliki free float kecil, oleh karena itu manajer investasi, dana pensiun dan asuransi merupakan pengguna utama dari IDX80 atas kebijakan free float yang akan datang sebagai acuan terutama untuk semua produk Exchange Traded Fund (ETF). Sementara pada perdagangan sesi 19 November 2018 diinformasikan oleh BEI tentang kondisi harga saham 10 emiten yang terkena pengurangan pembobotan dari indeks IDX30 pada 2018 ketika surat edaran BEI ini dirilis.

Dari sepuluh emiten ini, ada satu emiten yang jika di hubungkan dengan kebijakan free float tahun 2014 dalam penelitian penulis yaitu Pengaruh Kepemilikan Saham Terhadap Kinerja Perusahaan Sebelum dan Sesudah Kebijakan Free Float (Study Kasus Pada Emiten Yang Tidak Free Float). Hal inilah yang membuat penulis ingin melanjutkan penelitian ini untuk kasus yang sejalan. Oleh sebab itu mengadopsi dari penelitian penulis sebelumnya dimaksudkan untuk terus mengupdate kebijakan ini dan melihat perkembangannya terhadap kepemilikan saham, kinerja keuangan serta harga saham.

\section{Rumusan Masalah}

Berdasarkan latar belakang penelitian bahwa dampak kebijakan free float adalah terhadap harga saham maka masalah dirumuskan sebagai berikut :

1. Apakah perubahan kebijakan free float berpengaruh terhadap harga saham pada saat pengumuman, penerapan dan saat kebijakan dilaksanakan?

2. Apa dampak perubahan kebijakan free float terhadap emiten?

\section{Batasan Masalah}

Pengaruh perubahan kebijakan free float terhadap harga saham pada IDX30 dan LQ45 memiliki batasan sebagai berikut.

1. Untuk mempermudah pembahasan tentang perubahan kebijakan free float, maka pembahasan dibagi kedalam tiga tahap, yaitu 
a. Tahap I (Saat Pengumuman Perubahan Kebijakan free float) pada bulan November 2018.

b. Tahap II (Penerapan Bobot $70 \%$ dan $40 \%$ FF) yaitu bobot $70 \%$ berlaku pada tanggal 1 Februari 2019 dan bobot $40 \%$ berlaku tanggal 2 Mei 2019.

c. Tahap III (Pelaksanaan 100\% FF) pada tanggal 1 Agustus 2019.

2. Data sampel penelitian disesuaikan dengan kebijakan free float yang berlaku, yaitu 10 emiten pada saat pengumuman perubahan kebijakan, 90 emiten pada saat penerapan bobot $70 \%$ dan $40 \%$ FF serta 42 emiten pada saat pelaksanaan $100 \% \mathrm{FF}$.

3. Saham yang diteliti adalah saham saham pada indeks IDX30 dan LQ45.

\section{Tujuan Penelitian}

Adapun yang menjadi tujuan penelitian ini adalah sebagai berikut :

1. Untuk menguji apakah perubahan kebijakan free float berpengaruh terhadap harga saham saat pengumuman, saat penerapan dan saat pelaksanaan.

2. Untuk menganalisa dampak perubahan kebijakan free float terhadap emiten.

\section{Manfaat Penelitian}

Adapun manfaat dari penelitian terhadap perubahan kebijakan free float yang diterbitkan BEI diharapkan mempunyai manfaat berikut.

1. Melakukan pengamatan dan penelusuran terkait perubahan kebijakan free float selama beberapa kali direvisi.

2. Melakukan pengamatan dan penganalisaan sejak diberlakukannya kebijakan free float mulai tahun 2004 sampai 2019.

3. Mengapresiasi aturan BEI yang telah mengikutsertakan manajer investasi, dana pensiun dan asuransi sebagai pengguna utama dari IDX80 atas kebijakan free float yang akan datang sebagai acuan terutama untuk semua produk Exchange Traded Fund (ETF).

\section{KAJIAN LITERATUR Definisi Free Float}

Menurut (Ngurah, 2018) Free Float adalah persentase saham dari suatu perusahaan yang Go Publik yang bisa dibeli oleh masyarakat. Free float suatu perusahaan menjadi penting bagi investor karena menyajikan data seberapa tinggi peluang frekwensi volatilitas suatu saham. Menurut (Tuncer, 2010) pengertian free float adalah saham perusahaan publik yang likuid karena dipegang oleh investor portofolio yang cenderung bersedia untuk memperdagangkan.

Free float merupakan sebuah rasio atau metode untuk menghitung pembobotan ulang index yang dapat dilakukan dengan formulasi FFAI (Free Float Adjustmen Index). FFAI merupakan formulasi baru yang diberlakukan oleh BEI untuk para emiten bagi pelaksanaan 100\%FF yang berlaku mulai 1 Agustus 2019. Adapun Formulasi FFAI sebagai berikut.

$$
\begin{aligned}
& \text { FFAI } \\
& =\frac{\text { Market Cap } \times \text { RFF }}{\text { Rata - Rata Kapitalisasi Pasar Indeks }} \times 100 \% \\
& \text { Sumber: Samuel Research } \\
& \quad \text { Keterangan: } \\
& \quad \text { Market Cap = Kapitalisasi Pasar } \\
& \text { RFF = Rasio Free Float }
\end{aligned}
$$

\section{Pasar Modal}

Menurut (Citra, 2007) "Pasar Modal merupakan situasi yang mana memberikan ruang dan peluang penjual dan pembeli bertemu dan bernegoisasi dalam pertukaran komoditas dan kelompok komoditas modal". Pasar Modal (Capital Market) adalah pasar keuangan untuk dana jangka panjang dan dalam arti sempit merupakan pasar yang 
konkrit. Pasar modal mempunyai perbedaan dengan pasar uang atau money market yang berkaitan terutama dengan instrumen keuangan jangka pendek dan merupakan pasar abstrak. Instrumen yang digunakan dalam pasar modal pada umumnya antara lain saham, obligasi, tim right.

Pasar modal dalam arti sempit adalah suatu tempat dalam pengertian fisik yang terorganisasi tempat efek diperdagangkan yang disebut Bursa Efek. Pengertian bursa efek atau stock exchange adalah suatu sistem yang terorganisasi yang mempertemukan penjual dan pembeli efek yang dilakukan baik secara langsung maupun melalui wakilnya. Fungsi bursa efek antara lain untuk menjaga kontinuitas pasar dan menciptakan harga efek yang wajar melalui mekanisme permintaan dan penawaran.

\section{Fungsi Pasar Modal}

Pasar modal makro ekonomi adalah sebagai sarana pemerataan pendapatan masyarakat melalui investasi untuk memperoleh keuntungan dari kepemilikan perusahaan dengan membeli saham perusahaan tersebut. Pasar modal juga memiliki fungsi bagi perekonomian disuatu negara. Menurut (Citra, 2007) pasar modal memiliki beberapa fungsi strategis yang menyebabkan lembaga ini mempunyai daya tarik baik bagi pihak yang membutuhkan dana, pihak yang memiliki dana, maupun pemerintah. Pemerintah sangat berkepentingan dalam pembinaan pasar modal karena dengan membaiknya kondisi pasar modal dapat mencegah terjadinya capital flight atau pelarian modal ke luar negeri. Bila disuatu negara tidak ada pasar modal kemungkinan besar akan terjadi capital flight karena tidak adanya sarana investasi bagi para pemilik dana. Oleh karena itu pasar modal mempunyai beberapa fungsi antara lain adalah
1. Sebagai sumber penghimpun dana

Kebutuhan dana perusahaan bias dipenuhi dari berbagai sumber pembiayaan, salah satu sumber dana yang bias dimanfaatkan oleh perusahaan adalah pasar modal selain sistem perbankan yang selama ini dikenal

2. Sebagai saran investasi

Pada umumnya perusahaan menjual surat berharga (saham atau obligasi) kepasar modal adalah perusahaan yang sudah mempunyai reputasi bisnis yang baik dan kredibel, sehingga efek-efek yang dikeluarkan akan laku diperjual belikan di bursa.

3. Sebagai pemerataan pendapatan

Pada dasarnya apabila perusahaan tidak melakukan go public, pemilik perusahaan terbatas pada personalpersonal pediri perusahaan yang bersangkutan. Dengan go public-nya perusahaan memberikan kesempatan kepada masyarakat luas untuk ikut serta memiliki perusahaan tersebut.

4. Sebagai pendorong investasi

Sudah merupakan kewajiban pemerintah untuk memajukan pembangunan dan perekonomian negaranya untuk meningkatkan pertumbuhan ekonomi dan memajukan pembangunan membutuhkan investasi besar. Pemerintah tidak akan mampu melakukan investasi sendiri tanpa dibantu oleh pihak swasta nasional dan asing.

\section{Saham}

Saham merupakan salah satu instrument pasar modal yang paling diminati investor karena memberikan tingkat keuntungan yang menarik. Saham dapat didefinisikan sebagai tanda penyetaan modal seorang atau sepihak (badan usaha) dalam suatu perusahaan atau perseroan terbatas. Dengan menyertakan modal tersebut, maka pihak tersebut memiliki klaim atass pendapatan perusahaan, klaim atas asset perusahaan 
dan berhak hadir dalam rapat umum pemegang saham (RUSP).

\section{Jenis-Jenis Saham}

Saham merupakan berharga yang paling popular dan dikenal luas di masyarakat. Menurut (Jogiyanto, 2003) beberapa jenis saham yaitu antara lain:

1. Ditinjau dari segi kemampuan dalam hak tagih atau klaim, maka saham terbagi atas

a. Saham Biasa (Common Stock)

Saham biasa adalah saham yang menempatkan pemilik yang paling junior sebagai penerima dividen, dan hak atas harta kekayaan perusahaan apabila perusahaan tersebut dilikuidasi.

b. Saham Preferen (Preferred Stock)

Saham preferen adalah saham yang memiliki karakteristik gabungan antara obligasi dan saham biasa karena bisa menghasilkan pendapatan tetap (seperti bunga obligasi) tetapi juga bias tidak mendatangkan hasil seperti ini dikehendaki oleh investor.

2. Dilihat dari cara pemeliharaannya saham dibedakan menjadi

a. Saham atas Unjuk (Bearer Stock)

Saham atas unjuk adalah pada saham tersebut tidak tertulis nama pemiliknya agar mudah dipindahtangankan dari satu investor ke investor lain

b. Saham atas Nama (Registered Stock)

Saham atas nama adalah saham yang tertulis dengan jelas siapa pemiliknya dan dimana cara peliharanya harus melalui prosedur tertentu.

3. Ditinjau dari kinerja perdagangannya, maka saham dapat dikategorikan menjadi
a. Saham
Unggulan
(Blue-chip Stock)

Saham unggulan adalah saham biasa dari suatu perusahaan yang memiliki pendapatan yang stabil dan konsisten dalam membayar dividen

b. Saham Pendapatan (Income Stock)

Saham pendapatan adalah saham biasa dari suatu emiten yang memiliki kemampuan membayar deviden lebih tinggi dari rata-rata dividen yang dibayarkan pada tahun sebelumnya

c. Saham Pertumbuhan (Growth Stock-Well Know)

Saham pertumbuhan adalah sahamsaham yang dari emiten yang memiliki pertumbuhan pendapatan yang tinggi, sebagai leader di industri sejenis yang mempunyai reputasi tinggi

d. Saham Spekulatif (Spekulative Stock)

Saham spekulatif adalah saham suatu perusahaan yang tidak bias secara konsisten memperoleh penghasilan yang tinggi di masa mendatang meskipun belum pasti.

\section{Nilai Harga Saham}

Menurut (Jogiyanto, 2005) menerangkan bahwa nilai suatu saham dapat dilihat dari tiga konsep yaitu

1. Nilai Nominal

Nilai nominal adalah nilai perlembar saham yang berkaitan dengan akuntansi dan hukum.

2. Nilai Buku

Nilai buku adalah nilai buku perlembar saham menunjukan nilai aktivitas bersih perlembar saham yang merupakan nilai ekuitas dibagi dengan jumlah lembar saham

3. Nilai Pasar

Nilai pasar adalah nilai perlembar saham yang ditentukan oleh permintaan dan penawaran yang berbentuk dalam bursa saham

\section{Kerangka Pemikiran dan Hipotesis}

Reaksi pasar yang muncul dari diterbitkannya kebijakan rasio free float sudah seharusnya memberikan dampak bagi pasar bursa. Oleh karena fenomena 
ini mempunyai sensitivitas pada bursa saham, maka berikut ini adalah kerangka pemikiran penulis.

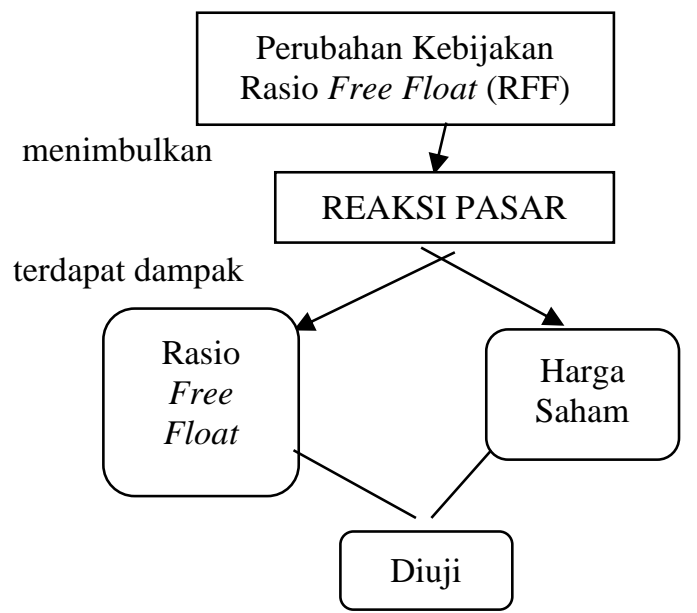

\section{Gambar 1. Kerangka pemikiran}

Maka hipotesis yang diajukan adalah sebagai berikut.

H0: Apakah Rasio free float (RFF) berpengaruh terhadap Harga Saham

H1: Apakah Rasio free float (RFF) tidak berpengaruh terhadap Harga Saham

Hipotesis yang diajukan digunakan untuk memenuhi pengujian terhadap tiga tahap perubahan kebijakan free float yaitu

1. Tahap I (saat pengumuman perubahan kebijkaan free float)

2. Tahap II (penerapan bobot $70 \%$ dan $40 \% \mathrm{FF})$

3. Tahap III (pelaksanaan 100\% FF)

\section{METODE PENELITIAN}

\section{Tahapan Penelitian}

Penelitian ini adalah penelitian dengan banyak memproses angka atau berdasar pada metode kuantitatif yang terdiri dari beberapa tahapan, antara lain

1. Menemukan masalah (Identifikasi Masalah)

2. Merumuskan masalah dengan konkrit

3. Membaca hasil penelitian sebelumnya yang relevan

4. Membaca teori dan konsep yang telah ada (Identifikasi Variabel)

5. Pengajuan hipotesis
6. Merumuskan hubungan antar variabel

7. Memilih strategi atau metode penelitian

8. Menentukan sample

9. Menyusun instrumen penelitian dan mengujinya

10. Mengumpulkan data dan menganalisa data

11. Korelasikan dengan hipotesis

12. Membuat kesimpulan

13. Membuat laporan hasil

Semua tahapan tersebut adalah proses yang harus dilakukan, untuk menyelesaikan studi kasus, penulis menggunakan data utama yang diperoleh dari survey dan pengamatan pada media internet seperti situs idx, situs para broker serta yahoo finance.

\section{Lokasi Penelitian}

Penelitian ini lebih banyak mengadopsi konsep dan teori sehingga data yang disajikan berupa angka-angka pada laporan keuangan dan harga saham dapat disediakan melalui on line internet. Untuk itu yang menjadi lokasi penelitian adalah kota Pontianak.

\section{Model Yang Digunakan}

Penelitian ini adalah penelitian dengan jenis eksplanatori dengan pendekatan kuantitatif. Penelitian eksplanatori adalah penelitian yang bertujuan untuk menguji suatu teori atau hipotesis guna memperkuat atau menolak teori atau hipotesis hasil penelitian yang sudah ada sebelumnya. Adapun bentuk penelitian berupa studi kasus pada emiten yang tidak free float di IDX30 dan LQ45. Selanjutnya metode statistik yang digunakan untuk menguji hipotesis adalah uji regresi dengan SPSS.

\section{Rancangan (desain) penelitian}

Rancangan penelitian pada penelitian eksplanatori adalah rancangan atau desain yg digunakan berikut mencantumkan hasil 
uji hipotesis untuk kemudian dianalisa dengan penelitian sebelumnya.

1. Tahap Identifikasi: Masalah diidentifikasi sebagai sebuah kebetulan, bahwa terdapat 10 emiten dari 30 emiten pada kelompok IDX30 yang tidak memenuhi rasio free float, dan emiten pada LQ45 yang terdampak pembobotan ulang kebijakan free float. Hal inilah yang menjadikan penelitian ini berbentuk studi kasus.

2. Tahap Menentukan Alat Pengujian: Hipotesis penelitian kemudian dibandingkan dengan hipotesis statistik, yaitu mengubah rumusan hipotesis naratif menjadi hipotesis statistik karena akan diuji dengan teknik statistik. Penelitian sebelumnya menghubungkan varabel rasio free float dengan tingkat kepemilikan saham, likuiditas saham serta pengaruh rasio free float terhadap kinerja perusahaan. Namun dalam penelitian ini, pada teknik statistik yang sama penulis berusaha menghubungkannya dengan harga saham oleh karena penulis fokus pada reaksi pasar ketika kebijakan ini direvisi.

3.Tahapan Hasil dan Publikasi

\section{Definisi Operasional variabel}

Berdasarkan tinjauan pustaka dan kerangka teoritis dan memperhatikan hipotesis yang diajukan, maka definisi operasional variabel penelitian dapat diidentifikasi sbb.

\section{Tabel 2. Identifikasi Variabel}

\section{Penelitian}

\begin{tabular}{|c|l|l|}
\hline No. & \multicolumn{1}{|c|}{ Variabel } & \multicolumn{1}{|c|}{ Pengukuran } \\
\hline 1 & $\begin{array}{l}\text { Rasio Free Float } \\
\text { RFF (X1) }\end{array}$ & $\begin{array}{l}\text { FFAI = Market Cap dikali } \\
\text { RFF dibagi Rata-rata } \\
\text { kapitalisasi pasar index } \\
\text { dikali 100\% }\end{array}$ \\
\hline 2 & $\begin{array}{l}\text { Harga Saham } \\
\text { HS (X2) }\end{array}$ & Harga Saham Penutupan \\
\hline
\end{tabular}

\section{Populasi dan Sampel}

Populasi dalam penelitian ini berjenis terbatas, pada tahap I (saat pengumuman ) ada 30 emiten pada kelompok IDX30 dan LQ45 dengan sifat homogen. Pada tahap II (saat penerapan bobot) yaitu ada 90 emiten dengan sifat homogen dan pada tahap III (saat pelaksanaan) ada 42 emiten dengan sifat homogen yang diamati.

Sampel dalam penelitian ini adalah 10 emiten yang tidak memenuhi rasio free float yaitu sampel dengan teknik pengambilan sampel berupa teknik sampel nonrandom, yaitu accidental sampling atau sampling kebetulan untuk menyelesaikan $\mathrm{n}$ data pada tahap I. Sedangkan pada tahap II terdapat 90 emiten dan tahap III terdapat 42 emiten.

\section{Teknik Pengumpulan Data}

Data untuk penelitian ini berasal dari

1. Studi Dokumentasi, yaitu berupa laporan keuangan para emiten di IDX30 dan LQ45, serta laporan harga saham harian emiten yang menjadi sampel data dalam penelitian.

2. Studi Literatur, yaitu berupa konsepkonsep teoritis yang berasal dari bukubuku yang berhubungan dengan tema penelitian.

\section{Analisis Data}

Analisis Data merupakan langkahlangkah dalam menyelesaikan masalah penelitian. Adapun Teknik Analisi Data yang dilakukan penulis sebagai berikut Menentukan kerangka pemikiran

1. Statistik inferensial

2. Mengajukan hipotesis

Hipotesis penelitian yang diajukan akan dilakukan uji regresi berganda dengan data yang berasal dari tahun 2018 dan 2019.

H0: Apakah Rasio free float (RFF) berpengaruh signifikan terhadap Harga Saham.

H1: Apakah Rasio free float (RFF) tidak berpengaruh signifikan terhadap Harga Saham. 
Hipotesis penelitian kemudian dibandingkan dengan hipotesis statistik, yaitu mengubah rumusan hipotesis naratif menjadi hipotesis statistik karena akan diuji dengan teknik statistik berikut ini:

- Uji Asumsi Klasik

- Uji Regresi Berganda

Yang akan diuji berikutnya adalah uji hipotesis nihil (H0) yaitu lawan dari hipotesis penelitian (H1).

\section{HASIL}

\section{Kebijakan Free Float}

Capitalization Weighted Index adalah bobot sebuah saham akan ditentukan dengan membagi kapitalisasi pasarnya dengan total kapitalisasi pasar dari seluruh saham pembentuk indeks. Kapitalisasi pasar dengan metode capitalizationweighted index (CWI) didapatkan dengan mengalikan seluruh saham yang beredar dengan harganya di pasar sekunder.

Sementara free float adjusted index adalah nilai kapitalisasi pasar yang diperoleh dengan cara mengalikan free float (total saham scripless yang dimiliki oleh investor dengan kepemilikan kurang dari 5\%) dengan harganya di pasar sekunder.

Kemudian, angka ini dibagi dengan total kapitalisasi pasar free float dari seluruh saham pembentuk indeks untuk mendapatkan bobotnya.

Adanya perubahan kebijakan ini dari tahun 2004 sampai tahun 2019 oleh BEI mempunyai tujuan untuk meningkatkan efisiensi portofolio, mendorong perusahaan untuk menambah porsi saham free float, serta mengurangi dominasi suatu saham dalam perhitungan indeks.

Perubahan kebijakan ini tentunya berimbas pada pasar modal berupa reaksi pasar. Reaksi pasar muncul karena adanya pembobotan ulang bagi para emiten karena diperbaharuinya rasio free float sesuai dengan kriteria yang diinginkan oleh BEI. Kriteria perubahan rasio free float disampaikan pada tabel berikut.

Tabel 3. Kriteria Perubahan

Kebijakan Free Float 2018/2019

\begin{tabular}{|c|c|c|c|}
\hline Kriteria & $\begin{array}{l}\text { Pengumuman } \\
\text { Perubahan } \\
\text { Kebijakan FF }\end{array}$ & $\begin{array}{l}\text { Penerapan } \\
\text { Bobot } 70 \% \\
\text { dan } 40 \% \mathrm{FF}\end{array}$ & $\begin{array}{l}\text { Pelaksanaan } \\
100 \% \text { FF }\end{array}$ \\
\hline Tahap & Tahap I & Tahap II & Tahap III \\
\hline Indeks & $\begin{array}{l}\text { LQ45 } \\
\text { dan } \\
\text { IDX30 }\end{array}$ & LQ45 & LQ45 \\
\hline $\begin{array}{l}\text { Tanggal } \\
\text { Berlaku }\end{array}$ & November 2018 & $\begin{array}{l}1 \quad \text { Februari } \\
2019 \text { (Bobot } \\
70 \%) \\
2 \text { Mei } 2019 \\
(\text { Bobot } 40 \%)\end{array}$ & $\begin{array}{ll}1 & \text { Agustus } \\
2019 & \end{array}$ \\
\hline $\begin{array}{l}\mathrm{n} \\
\text { sampel) }\end{array}$ & 10 & 90 & 42 \\
\hline $\begin{array}{l}\text { Pemangkasan } \\
\text { Emiten Tidak } \\
\text { Free Float }\end{array}$ & $\begin{array}{ll}10 & \text { Emiten } \\
\text { IDX30 } & \end{array}$ & Tidak Ada & Tidak Ada \\
\hline $\begin{array}{l}\text { Formulasi } \\
\text { Rasio Free } \\
\text { Float yang } \\
\text { digunakan }\end{array}$ & CWAI & FFAI & FFAI \\
\hline
\end{tabular}

Sumber: Data diolah

\section{PEMBAHASAN}

Apakah perubahan kebijakan free float berpengaruh terhadap harga saham pada saat pengumuman, penerapan dan saat kebijakan dilaksanakan

BEI telah beberapa kali melakukan perubahan kebijakan free float sejak tahun 2004. Tercatat menjadi kebijakan free float tahun 2004, 2014, dan 2018/2019 dengan indeks rasio free float yang berbeda beda. Penelitian yang penulis lakukan fokus atau mengupdate rasio free float yang terbaru.

a. Apakah perubahan kebijakan free float berpengaruh terhadap harga saham saat pengumuman

Kebijakan free float $10 \%$ dipublikasikan pada bulan November 2018. Pada saat itu BEI melakukan pemangkasan bagi emiten yang tidak memenuhi free float, dari LQ45 menjadi IDX30 dengan mengumumkan 10 emiten dari IDX30 yang tidak free float. Berikut adalah pembahasannya. 


\section{Analisis Regresi Berganda}

Berikut ini hasil analisis regresi berganda.

Tabel 4. Hasil Uji Regresi Berganda

$$
\mathbf{n}=\mathbf{1 0}
$$

Coefficients $^{\mathrm{a}}$

\begin{tabular}{|c|c|c|c|c|c|}
\hline \multirow{2}{*}{ Model } & \multicolumn{2}{|c|}{$\begin{array}{c}\text { Unstandardized } \\
\text { Coefficients }\end{array}$} & $\begin{array}{c}\text { Standardized } \\
\text { Coefficients }\end{array}$ & \multirow{2}{*}{$\mathrm{T}$} & \multirow{2}{*}{ Sig. } \\
\cline { 2 - 5 } & $\mathrm{B}$ & Std. Error & Beta & & \\
\hline 1 (Constant) & -7427.183 & 9606.402 & & -.773 & .462 \\
RFF & 17156.783 & 5890.063 & .717 & 2.913 & .020 \\
\hline
\end{tabular}

a. Dependent Variable: HS

Berdasarkan hasil uji regresi berganda di atas dapat disimpulkan bahwa Sig = 0,02 berada di bawah alpa 0,05 berarti dapat disimpulkan bahwa RFF berpengaruh terhadap HS pada saat perubahan kebijakan free float diumumkan. Dari 10 emiten yang terdampak tidak memenuhi free float dalam uji ini dinyatakan bahwa emiten tersebut free float-nya berpengaruh terhadap saham mereka.

\section{Uji Hipotesis}

Adapun pengujian hipotesa yang dilakukan peneliti dalam penelitian ini yaitu berupa Uji t. Uji t digunakan untuk mengetahui pengaruh variabel bebas secara parsial berpengaruh nyata atau tidak terhadap variabel dependen.

Tabel 5. Hasil Uji t Pada $n=10$

\begin{tabular}{|c|c|c|c|c|c|}
\hline \multicolumn{6}{|c|}{ Coefficients $^{\mathrm{a}}$} \\
\hline \multirow[t]{2}{*}{ Model } & \multicolumn{2}{|c|}{$\begin{array}{l}\text { Unstandardized } \\
\text { Coefficients }\end{array}$} & $\begin{array}{c}\text { Standardi } \\
\text { zed } \\
\text { Coefficie }\end{array}$ & \multirow[t]{2}{*}{$\mathrm{T}$} & \multirow[t]{2}{*}{ Sig. } \\
\hline & B & Std. Error & Beta & & \\
\hline 1 (Constant) & -7427.183 & 9606.402 & & -.773 & .462 \\
\hline RFF & 17156.783 & 5890.063 & .717 & 2.913 & .020 \\
\hline
\end{tabular}

a. Dependent Variable: HS

RFF terhadap Beta (Y) bahwa nilai sig. 0,02 lebih kecil dari nilai probabilitas 0,05 atau nilai $0,02<0,05$ maka RFF berpengaruh sig terhadap HS. Variabel RFF mempunyai $t$ hitung yaitu 2,913 dengan $\mathrm{t}$ tabel 2,306 Jika $\mathrm{t}$ hitung $>\mathrm{t}$ tabel dapat disimpulkan bahwa variabel RFF memiliki kontribusi terhadap Y (HS). Nilai t positif menunjukkan variabel RFF mempunyai hubungan searah dgn $\mathrm{Y}$, sehingga dapat disimpulkan RFF mempunyai pengaruh signifikan terhadap Beta, bahwa RFF mengalami penurunan bobot untuk mengurangi saham tidur pada saat kebijkaan ini diumumkan.

Hasil penelitian ini sejalan dengan hasil penelitian (Bonflio, 2014) yang fokus pada pengaruh free float terhadap likuiditas saham. Sementara hasil penelitian ini tidak sejalan dengan hasil penelitian (Kurnia, 2016) bahwa RFF tidak berpengaruh terhadap underpricing.

\section{b. Apakah perubahan kebijakan free float berpengaruh terhadap harga saham saat penerapan bobot $70 \%$ dan $40 \%$ FF}

Analisis Regresi Berganda

Berikut ini hasil analisis regresi berganda.

\section{Tabel 6. Hasil Uji Regresi Berganda} pada $\mathbf{n}=90$

\begin{tabular}{|l|r|r|c|c|c|}
\hline \multirow{3}{*}{ Model } & \multicolumn{2}{|c|}{$\begin{array}{c}\text { Unstandardized } \\
\text { Coefficients }\end{array}$} & $\begin{array}{c}\text { Standardized } \\
\text { Coefficients }\end{array}$ & \multirow{2}{*}{$\mathrm{T}$} & \multirow{2}{*}{ Sig. } \\
\cline { 2 - 4 } & \multicolumn{1}{|c|}{ B } & Std. Error & Beta & & \\
\hline (Constant) & 7201.391 & 2439.190 & & 2.952 & .004 \\
RFF & 730.659 & 528.428 & .214 & 1.383 & .174 \\
\hline
\end{tabular}
a. Dependent Variable: HS

Berdasarkan hasil uji regresi berganda di atas dapat disimpulkan bahwa Sig = 0,004 berada di bawah alpa 0,05 berarti dapat disimpulkan bahwa RFF berpengaruh terhadap HS pada saat perubahan kebijakan free float diterapkan pada bobot $70 \%$ dan $40 \%$ FF. Pada 90 emiten yang diteliti dalam uji ini dinyatakan bahwa emiten tersebut free float-nya berpengaruh terhadap saham mereka.

\section{Uji Hipotesis}

Adapun pengujian hipotesa yang dilakukan peneliti dalam penelitian ini yaitu berupa Uji t. Uji t digunakan untuk 
mengetahui pengaruh variabel bebas secara parsial berpengaruh nyata atau tidak terhadap variabel dependen.

Tabel 7. Hasil Uji t Pada $\mathbf{n}=90$

Coefficients $^{\mathrm{a}}$

\begin{tabular}{|c|r|r|c|c|c|}
\hline \multirow{3}{*}{ Model } & \multicolumn{2}{|c|}{$\begin{array}{c}\text { Unstandardized } \\
\text { Coefficients }\end{array}$} & $\begin{array}{l}\text { Standardized } \\
\text { Coefficients }\end{array}$ & $\mathrm{T}$ & Sig. \\
\cline { 2 - 7 } & \multicolumn{1}{|c|}{$\mathrm{B}$} & Std. Error & Beta & & \\
\hline 1 (Constant) & 17218.443 & 4655.721 & & 3.698 & .000 \\
RFF & -233.710 & 116.500 & -.209 & -2.006 & .048 \\
\hline
\end{tabular}

a. Dependent Variable: HS

RFF terhadap Beta (Y) bahwa nilai sig. 0,04 lebih kecil dari nilai probabilitas 0,05 atau nilai $0,04<0,05$ maka $\mathrm{RFF}$ berpengaruh sig terhadap HS. Variabel RFF mempunyai $\mathrm{t}$ hitung yaitu 3,698 dengan $\mathrm{t}$ tabel $1,990 \quad$ Jika $\mathrm{t}$ hitung $>\mathrm{t}$ tabel dapat disimpulkan bahwa variabel RFF memiliki kontribusi terhadap Y (HS). Nilai t negatif menunjukkan variabel RFF tidak mempunyai hubungan searah dgn Y.

Hasil penelitian ini sejalan dengan hasil penelitian Listyorini (2018) yang fokus pada pengaruh free float terhadap likuiditas saham. Sementara hasil penelitian ini tidak sejalan dengan hasil penelitian (Kurnia, 2016) bahwa RFF tidak berpengaruh terhadap underpricing.

\section{c. Apakah perubahan kebijakan free float berpengaruh terhadap harga saham saat pelaksanaan Analisis Regresi Berganda}

Berikut ini hasil analisis regresi berganda:

Tabel 8. Hasil Uji Regresi Berganda Pada $n=42$

\begin{tabular}{|l|r|r|c|c|c|}
\hline \multirow{2}{*}{ Model } & \multicolumn{2}{|c|}{$\begin{array}{c}\text { Unstandardized } \\
\text { Coefficients }\end{array}$} & $\begin{array}{c}\text { Standardized } \\
\text { Coefficients }\end{array}$ & \multirow{2}{*}{$\mathrm{t}$} & \multirow{2}{*}{ Sig. } \\
\cline { 2 - 4 } & \multicolumn{1}{|c|}{$\mathrm{B}$} & Std. Error & Beta & & \\
\hline (Constant) & 7201.391 & 2439.190 & & 2.952 & .005 \\
RFF & 730.659 & 528.428 & .214 & 1.383 & .174 \\
\hline
\end{tabular}
a. Dependent Variable: HS

Berdasarkan hasil uji regresi berganda di atas dapat disimpulkan bahwa Sig = 0,17 berada di atas alpa 0,05 berarti dapat disimpulkan bahwa RFF tidak berpengaruh terhadap HS pada saat penerapan kebijakan $100 \% \mathrm{FF}$.

\section{Uji Hipotesis}

Pengujian hipotesis dilakukan agar memperoleh kesimpulan dari analisis regresi linier berganda. Adapun pengujian hipotesa yang dilakukan peneliti dalam penelitian ini yaitu berupa Uji t. Uji t digunakan untuk mengetahui pengaruh variabel bebas secara parsial berpengaruh nyata atau tidak terhadap variabel dependen.

Tabel 9. Hasil Uji t Pada $n=42$

\begin{tabular}{|l|r|r|c|c|c|}
\hline \multirow{3}{*}{ Model } & \multicolumn{2}{|c|}{$\begin{array}{c}\text { Unstandardized } \\
\text { Coefficients }\end{array}$} & $\begin{array}{l}\text { Standardized } \\
\text { Coefficients }\end{array}$ & $\mathrm{t}$ & Sig. \\
\cline { 2 - 7 } & \multicolumn{1}{|c|}{$\mathrm{B}$} & Std. Error & Beta & & \\
\hline (Constant) & 17218.443 & 4655.721 & & 3.698 & .000 \\
RFF & -233.710 & 116.500 & -.209 & -2.006 & .048 \\
\hline
\end{tabular}

a. Dependent Variable: HS

RFF terhadap Beta (Y) bahwa nilai sig. 0,17 lebih besar dari nilai probabilitas 0,05 atau nilai $0,17>0,05$ maka RFF dalam penelitian ini diketahui tidak mempunyai pengaruh signifikan terhadap harga saham. Hal ini sejalan dengan penelitian (Tuncer, 2012) bahwa tidak ada pengaruh RFF terhadap Price Return. Berikut ini adalah ikhtisar pembahasan

Tabel 10. Ikhtisar Hasil Perubahan Kebijakan Free Float

\begin{tabular}{|c|c|c|c|}
\hline Kriteria & $\begin{array}{l}\text { Pengumuman } \\
\text { Perubahan } \\
\text { Kebijakan FF }\end{array}$ & $\begin{array}{l}\text { Penerapan } \\
\text { Bobot } \mathbf{7 0 \%} \\
\text { dan } \quad \mathbf{4 0 \%} \\
\text { FF }\end{array}$ & $\begin{array}{l}\text { Pelaksanaan } \\
100 \% \text { FF }\end{array}$ \\
\hline Tahap & Tahap I & Tahap II & Tahap III \\
\hline Indeks & $\begin{array}{l}\text { LQ45 } \\
\text { dan } \\
\text { IDX30 }\end{array}$ & LQ45 & LQ45 \\
\hline $\begin{array}{l}\text { Tanggal } \\
\text { Berlaku }\end{array}$ & $\begin{array}{l}\text { November } \\
2018\end{array}$ & $\begin{array}{l}1 \quad \text { Februari } \\
2019 \text { (Bobot } \\
70 \%) \\
2 \text { Mei } 2019 \\
\text { (Bobot } \\
40 \%)\end{array}$ & $\begin{array}{l}1 \text { Agustus } \\
2019\end{array}$ \\
\hline $\begin{array}{l}\mathrm{n} \text { (data } \\
\text { sample) }\end{array}$ & 10 & 90 & 42 \\
\hline $\begin{array}{l}\text { Hasil } \\
\text { Regresi }\end{array}$ & Sig. 0,02 & Sig. 0,04 & Sig. 0,17 \\
\hline
\end{tabular}




\begin{tabular}{|c|c|c|c|}
\hline & $\begin{array}{l}\text { Kebijakan } \\
\text { Free Float } \\
\text { berpengaruh } \\
\text { terhadap } \\
\text { Harga Saham }\end{array}$ & $\begin{array}{l}\text { Kebijakan } \\
\text { Free Float } \\
\text { berpengaruh } \\
\text { terhadap } \\
\text { Harga } \\
\text { Saham }\end{array}$ & $\begin{array}{l}\text { Kebijakan } \\
\text { Free Float } \\
\text { tidak } \\
\text { berpengaruh } \\
\text { terhadap } \\
\text { Harga Saham }\end{array}$ \\
\hline $\begin{array}{l}\text { Hasil Uji t } \\
\text { (Uji } \\
\text { Hipotesis) }\end{array}$ & $\begin{array}{l}\text { Sig. } 0,02 \\
\text { Kebijakan } \\
\text { Free Float } \\
\text { berpengaruh } \\
\text { signifikan } \\
\text { terhadap } \\
\text { Harga Saham } \\
\text { Nilai t positif } \\
\text { (RFF } \\
\text { mempunyai } \\
\text { hubungan } \\
\text { searah dengan } \\
\text { HS) }\end{array}$ & $\begin{array}{l}\text { Sig. 0,04 } \\
\text { Kebijakan } \\
\text { Free Float } \\
\text { berpengaruh } \\
\text { signifikan } \\
\text { terhadap } \\
\text { Harga } \\
\text { Saham } \\
\text { Nilai t t } \\
\text { negatif tidak } \\
\text { (RFF tida } \\
\text { mempunyai } \\
\text { hubungan } \\
\text { searah } \\
\text { dengan HS) }\end{array}$ & 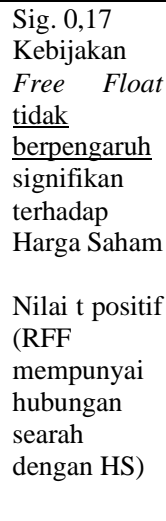 \\
\hline $\begin{array}{l}\text { Hasil Uji } \\
\text { Koefisien } \\
\text { Determinasi }\end{array}$ & \begin{tabular}{ll}
\multicolumn{2}{l}{0,717} \\
$\mathrm{R} \quad$ Adjust \\
0,454
\end{tabular} & $\begin{array}{l}\mathrm{R} 0,209 \\
\mathrm{R} \quad \text { Adjust } \\
0,033\end{array}$ & $\begin{array}{l}\mathrm{R} \quad 0,214 \\
\mathrm{R} \quad \text { Adjust } \\
0,022\end{array}$ \\
\hline $\begin{array}{l}\text { Saham yang } \\
\text { dirugikan }\end{array}$ & $\begin{array}{l}\text { HMSP, } \\
\text { GGRM } \\
\text { ANTM, JSMR }\end{array}$ & $\begin{array}{l}\text { HMSP } \\
\text { UNVR }\end{array}$ & $\begin{array}{l}\text { HMSP } \\
\text { UNVR } \\
\text { ICBP }\end{array}$ \\
\hline $\begin{array}{l}\text { Saham yang } \\
\text { diuntungkan }\end{array}$ & Perbankan & $\begin{array}{l}\text { Perbankan, } \\
\text { Industri } \\
\text { semen }\end{array}$ & $\begin{array}{l}\text { Perbankan, } \\
\text { Industri } \\
\text { semen } \\
\text { TLKM, } \\
\text { INDF }\end{array}$ \\
\hline
\end{tabular}

Hasil perubahan kebijakan free float diikhtisarkan pada tabel di atas mengisyaratkan bahwa kebijakan BEI mengenai pembobotan ulang harus dipandang sebagai peningkatkan efesiensi portofolio dengan berkurangnya bobot saham yang free float-nya rendah. Terlebih kebijakan ini diarahkan untuk mengurangi saham tidur. Harga saham sangat sensitif terhadap isu maupun kebijakan.

Perhatikan pada saat pengumuman perubahan kebijakan free float bulan November 2018, pasar saham seolah gaduh oleh karena hadirnya kebijakan pembobotan ulang ini sehingga emiten pada LQ45 merasa khawatir bahwa perusahannya tidak mampu mencapai rasio free float dengan standar $10 \%$ pada saat itu. Oleh karena itu emiten pada LQ45 terkesan seperti dipangkas menjadi IDX30 dimana 10 emitennya terdampak rasio ini. Emiten yang terdampak ini ada pada industri rokok seperti HMSP dan Gudang Garam. Sama halnya dengan industri pertambangan dan konstruksi. Tidak terlihat emiten dari sektor perbankan terkena dampak kebijakan ini. Terdeteksi berdasarkan pengamatan berkelanjutan adalah emiten HMSP, pada kebijakan free float 2004 dan 2014, HMSP merupakan satu-satunya emiten yang selalu terdampak dengan pembobotan ulang ini. (Kurnia 2014). Sensitivitas ini ternyata mempengaruhi harga saham sesuai dengan hasil uji statistiknya bahwa pada tahap ini rasio free float berpengaruh signifikan terhadap harga saham dengan tipe hubungan yang searah.

Pada saat penerapan bobot $70 \%$ dan $40 \%$ FF ditemukan bahwa RFF berpengaruh secara signifikan terhadap harga saham pada data sampel 90 yaitu jumlah LQ45 pada kedua bobot tersebut. Yang utama menjadi perhatian pada tahap ini adalah saham HMSP dan UNVR mengalami penurunan harga saham yang cukup signifikan. Adapun BEI menerapkan bobot $70 \%$ dan $40 \%$ FF ini bertujuan untuk

1. Bursa efek ingin mendorong perusahaan untuk meningkatakan saham free float-nya.

2. Meningkatkan efisiensi potofolio

3. Metode ini sudah menjadi standar umum bursa di luar negeri.

4. Memberikan gambaran rill saham yang bisa diperoleh investor, selain saham yang dimiliki oleh pengendali.

Pada saat pelaksanaan $100 \%$ FF ditemukan bahwa RFF tidak berpengaruh secara signifikan terhadap harga saham pada 42 emiten yang diamati. Pembobotan berlaku penuh $100 \%$ FF pada LQ45 dinilai akan mempengaruhi manajer investasi dalam mengelola portofolio reksadana, utamanya pada reksadana yang dikelola secara pasif seperti reksadana indeks dan Exchange Traded Fund (ETF). Pelaksanaan kebijakan secara penuh ini akan memaksa manajer investasi melakukan rebalancing atau pengaturan 
ulang komposisi reksadananya. Namun dirasakan pengaruhnya tidak secara langsung dan lebih bersifat temporer. Hal ini mengandung pengertian terdapat potensi tekanan pada kinerja reksadana berbasis indeks. Kalau saham dengan free float lebih besar lagi akan memberikan keuntungan bagi manajer investasi untuk membeli dan menyimpan sahamnya Dengan demikian atas dampak inilah BEI berencana mengembangkan LQ45 menjadi IDX80, yaitu indeks yang mengikutsertakan reksadana. Pelaksanaan $100 \%$ FF ini memicu perubahan dalam perhitungan kapitalisasi pasar pada LQ45 akan menurunkan bobot saham-saham yang lebih rendah free floatnya. Saham yang paling diuntungkan adalah saham perbankan seperti BBCA, BBRI, BMRI, serta saham seperti TLKM, ASII dan INDF. Sementara saham yang paling dirugikan akibat pembobotan ulang ini adalah saham-saham industri rokok seperti HMSP, GGRM serta saham consumer seperti UNVR, ICBP dan saham konstruksi seperti JSMR, TPIA dan BRPT.

\section{Dampak perubahan kebijakan free float terhadap emiten}

Penerapan bobot $70 \%$ dan $40 \%$ FF dan pelaksanaan kebijakan free float $100 \%$ sudah dilaksanakan bertahap, dengan adjustment (penyesuaian) terhadap pembobotan khususnya bagi sahamsaham yang berada dalam indeks LQ45 dan IDX30. Tujuan dari adjustment ini sebagai gambaran riil nilai saham yang bisa diperoleh para investor, dengan mengecualikan nilai saham yang dimiliki pemegang saham pengendali. Selain itu dengan adanya kebijakan free float yang terus di-update, diproyeksikan akan meningkatkan efisiensi portofolio dengan berkurangnya bobot saham yang free float-nya rendah.

Dampak perubahan kebijakan free float terhadap emiten bisa dikatakan tidak ada dampak yang cukup signifikan terhadap penurunan harga saham. Rasio free float bukanlah variabel utama yang berpotensi menurunkan harga saham, namun harga saham bisa turun dengan disebabkan oleh beberapa faktor lainnya.

Berikut ini beberapa dampak perubahan kebijakan free float terhadap emiten.

1. Emiten harus menjaga penilaian kualitatif seperti kinerja keuangan, kepatuhan, dan lainnya serta teknik fundamental saham yang baik agar harga saham tidak mengalami penurunan saat diperdagangan di bursa.

2. Emiten harus menjaga penilaian kuantitatif dalam formulasi Free Float Adjustment Index (FFAI) agar bobotnya tidak turun. Jika bobot saham emiten turun bukan juga berarti fundamental saham emiten menjadi jelek.

3. Emiten arus menjaga likuiditas saham dan fundamental saham agar bernilai tetap untuk memenuhi free float.

4. Investor bisa memilih saham dengan free float besar karena punya potensi likuiditas yang bagus.

5. Bobot saham suatu perusahaan bisa naik jika:

a. Rasio free float naik atau bertambah

b. Rata-rata kapitalisasi pasar indeks turun, sedangkan faktor lainnya tetap

c. Kapitalisasi pasar perusahaan bertambah besar

\section{SIMPULAN}

Berdasarkan hasil penelitian dan pembahasan mengenai perubahan kebijakan free float terhadap harga saham maka penulis berkesimpulan sebagai berikut.

1. Hasil uji hipotesis pada saat pengumuman menyatakan bahwa rasio free float 
berpengaruh terhadap harga saham sebesar 0,02 dengan merugikan saham industri rokok dan pertambangan. Pada tahap ini saham yang diuntungkan dari kebijakan tersebut adalah saham perbankan seperti BBCA dan BBRI. Sementara itu pada saat penerapan bobot $70 \%$ dan $40 \%$ FF menyatakan bahwa rasio free float berpengaruh terhadap harga saham sebesar 0,04 dengan merugikan industri rokok dan consumer goods. Adapun saham yang diuntungkan adalah saham perbankan dan industri semen. Untuk pelaksanaan $100 \%$ FF menyatakan bahwa rasio free float tidak berpengaruh terhadap harga saham sebesar 0,17 dengan kembali merugikan industri rokok dan sektor konstruksi. Sementara pada tahap ini saham yang diuntungkan dengan penerapan $100 \%$ penuh rasio free float adalah saham perbankan, industri semen, dan telekomunikasi.

2. Dampak perubahan kebijakan free float terhadap emiten bisa dikatakan tidak ada dampak yang cukup signifikan terhadap penurunan harga saham. Rasio free float bukanlah variabel utama yang berpotensi menurunkan harga saham, namun harga saham bisa turun dengan disebabkan oleh beberapa faktor lainnya. Dampak perubahan kebijakan ini dapat diminimalisir jika penilaian kualitatif dan fundamental cukup baik, maka harga saham tidak akan mempengaruhi emiten untuk melakukan perdagangan di bursa. Penilaian kuantitatif dalam formulasi Free Float Adjustment Index jika bobotnya turun bukan berarti fundamental saham emiten menjadi jelek. Kemungkinan para emiten hanya merasa panik sesaat sebagai reaksi pasar saham yang wajar. Namun jika likuiditas saham dan fundamental saham bernilai tetap bukan berarti emiten tidak mampu memenuhi rasio free float. Kebijkaan free float memberikan gambaran kepada investor tentang kondisi likuiditas saham jika dilihat dari bobotnya sehingga investor bisa memilih saham dengan free float besar karena punya potensi likuiditas yang bagus. Untuk memastikan bobot saham suatu perusahaan bisa naik maka rasio free float harus naik atau bertambah, rata-rata kapitalisasi pasar indeks turun, sedangkan faktor lainnya tetap dan kapitalisasi pasar perusahaan bertambah besar.

\section{REFERENSI}

Ang, Robbert, 1997, Buku Pintar : Pasar Modal Indonesia (The Intelligent Guide To Indonesian Capital Market), First Edition, Jakarta : Mediasoft

Busman, Robert M, 2001, Financial Accounting Information and Corporate Goverance, Journal of Accounting and Economics, Page $237-333$

Bonflio Benvenuto Sebayang, Wenny Setiawan, 2014, Analisis Yudiris Mengenai Ketentuan Free Float Terkait Perubahan Peraturan BEI No. I-A dan Perbandingan Praktek Free Float Di Negara Singapura, India, dan Inggris, Skripsi, Universitas Muhammadyah Yogyakarta

Citra Handayani, 2007, Analisis Pengaruh Proporsi Kepemilikan Saham Terhadap Kebijakan Pendanaan Dalam Meningkatkan Kinerja Perusahaan, Thesis, Universitas Diponegoro

Durbin, J., dan Watson, G.S., 1951. Testing for Serial Correlation in Least Square Regression. Biometrika, Vol. 38. Hlm. 159 - 177

Fitrijanti, Tettet dan Hartono, Jogiyanto 2002, Set Kesempatan Investasi : Konstruksi dan Analisis Hubungannya dengan Kebijakan Pendanaan dan Devidend, Jurnal Riset Akuntansi Indonesia, Vol 5 No: $1: 35-63$ 
Finansial (2018). Dampak Penerapan Free Float [Online]. Tersedia : https://www.finansialku.com/penera pan-free-float-pada-lq45-dan-idx30/ Diakses tanggal 10 Desember 2018

Ghozali, I. 2001. Aplikasi Analisis Multivariative Dengan Program SPSS. Badan Penerbit Universitas Diponegoro

Gujarati, D.N. 1995. Basic Econometrics. $3^{\text {th }} \quad$ edition. McGraw-Hill International Edition.

Indriantoro, N., dan B. Supomo. 1999. Metodologi Penelitian Bisnis untuk Akuntansi dan Manajemen. Edisi Pertama. Yogyakarta : BPFE

Jogiyanto, H.M. 2003. Teori Portofolio dan Analisis Investasi. Edisi 3. Yogyakarta: BPFE 2005. Pasar Efisiensi Secara

Keputusan. Jakarta: PT Gramedia Pustaka Utama

Kurnia Elizer, Aryapranata, 2016, Pengaruh Reputasi Auditor, Reputasi Underwriter, dan Persentase Free Float Terhadap Tingkat Underpricing Pada Intial Public Coffering (Studi Empiris Pada Perusahaan yang Go Public di Bursa Efek Indonesia Periode Tahun 2012-2014), Skripsi, Universitas Diponegoro Semarang

Lamber, Richard A, 2001, Contracting Theory and Accounting, journal of accounting Economics, 32 (2001) : 3 $-87$

Ngurah Warman (2018). Pengertian Free Float [Online]. Tersedia : https://pintarsaham.id/apa-yangdimaksud-dengan-free-float-dalam-

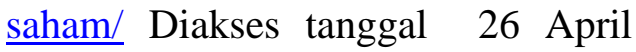
2018

Ninik. Sari. Rika (2015) Pengaruh Kepemilikan Saham Terhadap Kinerja Perusahaan Sebelum dan Sesudah Kebijakan Free Float Pada Emiten Yang Tidak Free Float.
Proceeding Seminar Nasional Akuntansi Vokasi ke 4 Manado Santoso, S. 2000. Buku Latihan SPSS Statistik Parametrik. PT Elex Media Komputindo Kelompok Gramedia. Jakarta

Suad Husnan, 2001, Corporate Governance dan Keputusan Pendanaan : Perbandingan Kinerja Perusahaan dengan Pemegang sham pengendali Perusahaan Multinasional dan Bukan Multinasional, Jurnal riset Akuntansi, Manajemen, ekonomi, Vol : 1 No: 1 Februari 1 - 12

Suranta, Eddy dan Midiastuti, Puspa , 2003, Analisis Hubungan Struktur Kepemilikan Manajerial, Nilai Perusahaan dan Investasi dengan model ;persamaan Linier Simultan, Jurnal riset Akuntansi Indonesia Vo : 6 No: 1 Januari 54 -68

Sulistiono, 2010, Pengaruh Kepemilikan Managerial, Struktur Modal dan Ukuran Perusahaan Terhadap Nilai Perusahaan Pada Perusahaan Manufaktur di BEI 2006-2008, Skipsi, Universitas Negeri Semarang

Suria Dharma, 2019, Free Float Adjustment : Final Adjustment On August, Thematic Report, Jakarta : Samuel Equity Reseacrh

Teddy Pratomo. (2007). Analisis Pengaruh Kepemilikan Saham dan Konsentrasi Kepemilikan Terhadap Struktur Modal Serta Dampaknya Terhadap Kinerja Keuangan. Skripsi. UI

Tuncer Caliskan. 2010. Effect of Free Float Ratios on Stock Prices an Application on ISE. Journal Dogus. Universitesi Berginsi. 